\title{
Entering Academic Psychiatry: A Resident's Perspective
}

Julio Licinio, M.D.

Veterans Affairs Medical Center, West Haven, Connecticut

Follow this and additional works at: https://jdc.jefferson.edu/jeffjpsychiatry

Part of the Psychiatry Commons

Let us know how access to this document benefits you

\section{Recommended Citation}

Licinio, M.D., Julio (1993) "Entering Academic Psychiatry: A Resident's Perspective," Jefferson Journal of Psychiatry. Vol. 11 : Iss. 1 , Article 6.

DOI: https://doi.org/10.29046/JJP.011.1.003

Available at: https://jdc.jefferson.edu/jeffjpsychiatry/vol11/iss1/6

This Article is brought to you for free and open access by the Jefferson Digital Commons. The Jefferson Digital Commons is a service of Thomas Jefferson University's Center for Teaching and Learning (CTL). The Commons is a showcase for Jefferson books and journals, peer-reviewed scholarly publications, unique historical collections from the University archives, and teaching tools. The Jefferson Digital Commons allows researchers and interested readers anywhere in the world to learn about and keep up to date with Jefferson scholarship. This article has been accepted for inclusion in Jefferson Journal of Psychiatry by an authorized administrator of the Jefferson Digital Commons. For more information, please contact: JeffersonDigitalCommons@jefferson.edu. 


\title{
Entering Academic Psychiatry: A Resident's Perspective
}

\author{
Julio Licinio, M.D.
}

\begin{abstract}
University-based psychiatry residency programs encourage the pursuit of academic careers, both on admission, by favoring applicants with evidence of a commitment to investigation, and after residency training, by selecting as faculty residents who have demonstrated academic and research productivity. While attempting to achieve multiple goals, some residents may be discouraged to pursue an academic career as a result of marked conflict between the clinical and academic components of training. The substantial differences in priorities among psychiatry residents ought to be explored early in residency training by devoting seminars to career planning and by facilitating the pursuit of academic activities under a preceptorship program. Furthermore, the option for research track residency programs should be available to those with a strong commitment to academic psychiatry.
\end{abstract}

In the past 15 years medical educators and researchers have been increasingly concerned about the future of academic medicine (1-9). Such concern stems from various threats to the academic medical establishment, including financial constraints (10), litigation issues (11), insufficient funds to support research $(12,13)$, and a decline of interest by medical students and residents to pursue a clinical research academic career $(1,3,9,14,15)$. The trend towards fewer physician-investigators has been identified in the U.S. and worldwide (16).

Wyngaarden (1) addressed the declining interest in biomedical research on the part of young physicians. He pointed out that physician-investigators are an endangered species, basing this statement on the substantial decline of the proportion of federal postdoctoral fellowships awarded to M.D.'s (physician-scientists) compared with those granted to Ph.D.'s (non-physicians biomedical scientists), from $46 \%$ in 1977 to $20 \%$ in 1986 . By 1977 , of 2800 postdoctoral fellowships in the clinical sciences, only 2304 were filled, and 500 positions were not used. The proportion of federal research grants awarded to principal investigators who are physician-scientists also declined, from $43 \%$ in 1966 to $32 \%$ in 1977 . A more recent article in the American Journal of Medicine compares academic physicians to dinosaurs, struggling to survive (17). In the 80's federal research support to M.D.'s continued to decline; by $198768 \%$ of all NIH grants were awarded to investigators with a Ph.D.

Strong recommendations to correct the decline in number of those entering clinical investigation have been made, including economic incentives and reexamina- 
tion of Board certification requirements so that appropriate credit be given to research training in residency training programs. A decade and a half after Wyngaarden's paper, the situation has only worsened. Healy, the current NIH director, has published a report on the manpower crisis in biomedical research (9). In 1987 the proportion of physicians who were principal investigators on federal research grants further declined to 26\%. Both Wyngaarden (1) and Healy (9) point out that clinician-investigators are declining by choice: for the past 20 years M.D.'s and Ph.D.'s principal investigators on applications for federal research funds have had virtually identical award rates, therefore the physician-scientists increasingly smaller success in obtaining grants is due to the progressive decline in the total number of physicians applying for grants, as a percentage of the total. Their conclusion is that physicians are deciding not to enter research.

In spite of the declining interest in biomedical research on the part of medical students and residents, the need for qualified clinician-investigators has been quite significant in the last two decades. Wyngaarden stated that in the 70's the numbers of medical-school graduates and full-time faculty in U.S. medical schools have doubled, but between 1966 and 1975 the number of American physicians reporting research as their primary activity declined from 15,441 to 7,944 (1). According to the National Research Council, there has been a demand for an "annual increment of approximately 1,800 persons to meet the requirements created by expansion and at trition of clinical faculties in medical schools over the next few year" (18). In view of this fact, there has been in recent years considerable discussion in the medical education literature on the facilitation of the formation of clinician-investigators in medicine in general $(1-3,6,8)$, and in psychiatry in particular (19-22). On the other hand, a comprehensive review of the literature in the last ten years did not show any work attempting to analyze the transition from training to academia from the point of view of the trainee. This paper examines issues encountered in my own training in a research-track residency program in psychiatry. My experience in the transition from trainee to independent investigator will be examined, and suggestions will be made to facilitate the training of those interested in pursuing an academic career in psychiatry.

The need for qualified clinician-investigators in medicine in general $(6,8,10)$ and in psychiatry in particular $(20-22)$ is not new $(1,2,19)$. The need for clinicianinvestigators is especially significant in psychiatry. In the past thirty years there has been a trend in psychiatric research for growing sophistication in research design, as documented by the significant increases in percentages of cohort, clinical trials, and cross-sectional studies published in the Archives of General Psychiatry and the American Journal of Psychiatry. The quality of research designs in psychiatry for 1983 also compared favorably with research designs found in a respected medicine journal (23). Therefore, when published data is analyzed there appears to be an overall improvement in the quality of psychiatric research in the past thirty years. However, when the research productivity of academic departments of psychiatry is examined, it becomes clear that the trend for increasingly sophisticated research in psychiatry is due to a 
core group of academic departments. About $77 \%$ of grants awarded by the National Institutes of Mental Health (NIMH) are won by just $10 \%$ of the departments of psychiatry, and nearly half of all psychiatry departments in the USA are without a single research grant awarded by NIMH (20). Furthermore, when compared to a pool of general medicine physicians (internal medicine, family practice, obstetricsgynecology, and dermatology, $n=14,090)$, only $12 \%$ of psychiatry faculty $(n=2429)$ had research training, versus $34 \%$ of those in general medicine. In addition, in academic general medicine $13 \%$ of all physicians are principal investigators on federal research grants compared with only $5 \%$ in psychiatry (20).

To stimulate the formation of clinician-investigators the American Association of Medical Colleges has recommended that "medical schools should encourage program directors to provide flexibility in residency schedules for trainees desiring research experience" (14). A survey of residency programs indicates that research track residency programs in psychiatry are available at several academic departments of psychiatry, such as The New York Hospital-Cornell Medical Center, Yale University, University of Michigan, Stanford University, University of TexasGalveston, and others.

I completed residency training in the research-track residency program at The New York Hospital-Cornell Medical Center, Westchester Division. In that program the core clinical training in psychiatry was supplemented with extra elective time to develop and conduct research. At the beginning of the program I chose a research preceptor who worked with me throughout the program. Elective courses in biostatistics and research design were available. I was the first resident to participate in that program, and my experience was very positive; the research elective time allowed me to work with my preceptor on the design, implementation, approval, and funding application for my research. The experience was far more productive than anything that would have been possible in a traditional curriculum. On the other hand, my role in the clinical rotations was sometimes unclear. Many faculty supervisors were aware that there was a research-track program in our hospital, however did not know I was part of it. In spite of this the arrangement worked very smoothly as I fully participated in all the core clinical rotations. In my fourth year of training, when the strongest didactic courses are offered, I was conducting my studies and analyzing my results. Therefore I felt a conflict between attending core and elective didactic courses, and doing the required reading, and conducting my own research studies. At times I questioned: do I read a paper required for an elective seminar or do I conduct an experiment? Using my own judgment to optimize both experiences, I did not attend as many seminars or read as many papers as I wish I could have, and I did not conduct as many experiments as possible; however, overall I did participate in a number of didactic activities and was also able to gain substantial experience conducting clinical psychiatric research studies. In my opinion, the most important skills I gained resulted from this apparent time conflict: learning to manage one's time effectively, and negotiating teaching, research, and clinical commitments which are crucial to those in academic medicine. 


\section{ISSUES RELATED TO THE TRAINING OF ACADEMIC PSYCHIATRISTS}

\section{Training Structure}

In a research residency program, four options have been suggested to combine research and patient care (8). 1) Epidemiology research: residents would have research training on epidemiological design, with electives in epidemiology, biostatistics, and experimental design. 2) Clinical biomedical research: residents would be intermediaries between the laboratory and the clinic: they would learn to be physicians who understand research, translate it into clinical problems, test hypotheses, and bring ideas back to the laboratory. 3) Basic biomedical research on a disease-related topic: residents would learn pre-clinical research techniques applied to research on a specific disease, and would have in-depth clinical experience with patients suffering from that disease. 4) Basic biomedical research with no concomitant clinical responsibilities.

From a structural point of view, Pincus, the current Director of the Office of Research, American Psychiatric Association, has indicated that to meet the critical, ongoing need for clinically trained investigators who can provide a bridge between the basic and clinical sciences, the following points have to be addressed: recruitment, preparation, retention, mentoring, creation of social support and reward systems, and need for federal programs. Pincus further suggested that departments of psychiatry should actively promote research opportunities for residents and medical students and discusses them extensively (24). It is important that early in their careers, investigators-to-be acquire familiarity with different psychiatric research methodologies (25). A survey of 516 "successful" clinical investigators showed that a decision to follow a research career is made in the early part of training and is related to early research experiences (26). Furthermore, early research experience is highly correlated to following an academic career (27). Learning research procedures is important not only to motivate trainees to start an academic career but also serves as a foundation for further development. Golstein, in his presidential address delivered before the 78th Annual Meeting of the American Society for Clinical Investigation, addressed the common issue of a mid-career investigator suffering from PAIDS (paralyzed academic investigator's disease syndrome), caused by insufficient research training during the early phases of a research career and leading to long-term stagnation in research productivity (7). As psychiatric research methodology has evolved in recent decades $(23,28-30)$, there is a growing need for good psychiatric research training during medical school and residency so that both recruitment into academic psychiatry and continued research excellence can be maintained. Experience in several branches of medicine indicates that recruitment and early training are necessary but not sufficient; once the transition to research is accomplished, ways to retain young investigators ought to be developed (24,31).

The clinically trained physician has the insight to transfer knowledge gained through research to the patient. Conversely, many research projects start from ideas sparked by a physician who encounters a particular patient problem. The advantage 
of clinician-investigators is their clinical training, which remains the most important component of residency programs, allowing them to bridge research and patient care (14). In psychiatry, in particular, a deep understanding of clinical issues is essential in the formulation and elucidation of research questions such as the nature of neurobiological defects in depression or schizophrenia, design, monitoring, and interpretation of techniques for measuring course and outcome (20). Trying to answer questions encountered in clinical practice with good research methodology is a challenge that has traditionally attracted physicians to careers in clinical investigation (33). Interestingly, a survey of all members of the US medical school classes of 1980 showed that seniors listed as the factors influencing the choice of a research career in order of highest importance were: 1) opportunity to work in the academic community; 2) challenge of search for new knowledge; 3 ) research experience while a premedical or medical student; 4) availability of training research support. As a whole the 1980 seniors considered of minor importance four factors generally assumed to be deterrents to a career in clinical investigation: 1) the uncertain availability of research funds after completion of training; 2) the financial disadvantages of a research career; 3) the obligation to pay back research training by continued research activity; 4) the increasing frustration of investigators in conducting clinical research. These last four points may be of greater importance a few years later when students as residents or fellows face the realities of a decision to pursue a research career (3).

\section{Multiple Roles of the Academic Physician}

In commercial enterprises, management, production, and sales are concentrated in different departments; however in academia, the physician has to to wear simultaneously the hats of manager, producer, and sales person. The difficulty of combining those hats is particularly great for clinician-investigators. U.S. academic physicians after the post-World War II era traditionally pursued research, teaching, and patient care (17). In the last forty years this tradition has been seen as the ideal for the university-hospital based physician. In the early 1990's the tremendous expansion of biomedical research and changes in the economic and social realities of clinical practice make it hardly possible for the academic physician to pursue a balanced career of research, teaching, and patient care. Reimbursement for these activities is also a major problem. Federal training grants to residency programs in psychiatry no longer exist so that teaching is not generally reimbursed. Income is generated for academic physicians by clinical billing and research grants. It is well described that clinical reimbursement, especially for mental health, is in a state of crisis. Psychiatric hospitalization is closely monitored by insurance companies and reimbursement for needed mental health clinical services is now closely managed by most insurance plans. The effects of a possible health care reform, being orchestrated by the current administration, on the availability and payment for clinical psychiatric services remain to be determined. On the other hand, research funding is now extraordinarily competitive. Psychiatry research has been predominantly funded by 
the federal government. The mental health and substance abuse institutes are now part of NIH. Movsesian reported that in 1990 of new, peer-reviewed and approved investigator-initiated research grant applications submitted to NIH only one in seven is funded (34). In the last review cycle, only one out of every eleven approved research grants submitted to NIMH was funded. In this highly stressful climate the strain on experienced academic physicians is substantial. For those in training the highly pressured environment of academic medicine, and academic psychiatry, may be experienced as overwhelming.

Healy has stated that the triple mission of academic medicine, namely, research, teaching, and patient care, has actually become a triple threat: "as basic research becomes more sophisticated and methodologically complex, and practice more specialized, and oriented towards technology, the physician scientist who can do justice to all three is becoming a vanishing breed" (9). A "tug-of-war" among research, teaching, and clinical practice will not solve the current manpower problems in academic medicine. Healy recommends removing the strain from the individual physician to be simultaneously a great clinician, a great researcher, and a great teacher. Career differentiation should be emphasized and the burden of the triple mission should shift from the individual faculty member to the academic department as a whole.

\section{Hospital Versus Medical School}

Recent research indicates that the training of future clinical investigators occurs predominantly in university-hospital settings, exposure to research during training being an important factor that motivates students and residents to pursue careers in clinical investigation (27,35-37). A recently published longitudinal cohort study of career achievement among academic physicians showed that research experience in medical school was independently associated with having chosen an academic career (27). This finding is comparable to what had been found by previous studies conducted in this country and abroad. A survey of all medically-qualified faculty members in the U.K. (professors and readers, $n=940$ ) showed that those with undergraduate research achievements had a better publication record over ten years (median number of original publications $=72$ ) than those without such a record (median $=46$ ) (37). In Australia, graduates of the University of Queensland Bachelor of Medical Sciences program, which provides medical students with laboratory based research training, were significantly more likely to enter full-time academic medicine or research than other medical graduates $(20 \%$ versus $0.9 \%$, p $<0.001$ ) (38). In the US, 76\% of the graduates of Duke University School of Medicine Medical Scientist Training Program (M.D.-Ph.D.) $(n=75)$ followed careers in academic medicine or in research, compared to $8-9 \%$ of the total number of physicians in the US ( $n=570,00)$ who are members of full-time clinical faculties (39). In a survey of all departments of internal medicine in the US, $71.6 \%$ of all medically-qualified faculty $(n=6749)$ had had more than one year of research training, and $75 \%$ of faculty with 
only a medical degree $(n=6237)$ reported research activity in the academic year 1982-1983 (35).

For those in university-based postgraduate training programs there may be a conflict between the medical school and the hospital. Residents are hospital employees, paid and penalized according to hospital rules and regulations. Increased cost-containment measures (10), and the problems related to litigation have led hospitals and even the New York State Legislature to be very strict in relation to resident activities (11). Failure to fulfill increasingly stringent bureaucratic requirements may lead to penalties. As a result housestaff tend to have as a priority the fulfillment of hospital requirements.

Time spent dealing with medical records, quality assurance, and documentation of need for and delivery of care may prevent penalties but it will not lead to academic promotion (6). Promotion is recommended according to the requirements of the medical school, which are related to research productivity. Young investigators are constantly pressured to publish in order to advance their academic careers (40). Faculty members supervising residents are not aware in many instances that the conflict between the requirements of the hospital and those of the medical school are already a problem for the housestaff, especially for those interested in pursuing a clinical research career. Those issues, if discussed at all, tend to be left for faculty meetings from which residents are excluded.

\section{CONCLUSIONS}

The early acquisition of research skills is important in motivating trainees to pursue careers in clinical investigation and also to ensure continued excellence in research throughout an academic career in psychiatry. Residency programs need seminars devoted to career planning in order to explore different careers paths for trainees. Those seminars should address the following four points related to careers that combine research and clinical care (8): 1 . What will compose basic medical research in the future? 2. What careers are feasible for a physician who wants to combine research and patient care? 3 . What training pathways for such careers are available or needed? 4 . How are these careers displayed and supported? Those who have potential for and interest in pursuing a career in clinical investigation would benefit from a research preceptorship program, in which a senior investigator supervises the resident throughout his training. Furthermore, the option of alternative programs, such as a five-year research-track residency, should be available for those with a strong commitment to academic psychiatry. Academic departments of psychiatry could also facilitate early research experience by providing initial funding for those pilot studies, secretarial, and data processing support systems, faculty supervision, and defined curricular time for research during residency training (42). The degree of availability of those resources could then vary between the traditional curriculum and research-track residency training programs. 


\section{REFERENCES}

1. Wyngaarden JB: The clinical investigator as an endangered species. N Engl Med 1979; 301:1254-1259

2. Landau RL: Clinical research: elements for a prognosis. Perspect Biol Med 1980; 23:S3-8

3. Wyngaarden JB: Encouraging young physicians to pursue a career in clinical research. Clin Res 1983; 31:115-118

4. Langley GE: A threat to psychiatric research. Br. Med J 1986; 293:13-134

5. Littlefield JW: On the difficulty of combining basic research and patient care. AM J Hum Genet 1984; 36:731-7355

6. McGaghie WC \& Frey JJ: Handbook for the Academic Physician. New York, SpringerVerlag, 1986

7. Goldstein JL: On the origin and prevention of PAIDS (paralyzed academic investigator's disease syndrome). J Clin Invest 1986; 78:848-854

8. Littlefield JW: The need to promote careers that combine research and clinical care. J Med Educ 1986; 61:785-789

9. Healy B: Innovators for the 21 st century: Will we face a crisi in biomeidical-research manpower? N Engl J Med 1988; 319:1058-1064

10. Rothschild VM, Clayton T: Highlights of the 37th Institute on Hospital and Community Psychiatry. Hosp Community Psychiatry 1986; 37:17-20

11. Asch DA, Parker RM: The Libby Zion case. One step forward or two steps backwards? N Engl J Med 1988; 318:771-773

12. Golden WE, Olive DA, Frieddlander IR: Megatrends in medical education. Am J Med 1986; 81:112-116

13. Swales J: What has happened to academic medicine. Lancet 1986; i:1194-1196

14. Thier SO, Challoner DR, Cocckerham J, et al: Proposals addressing the decline in the training of physicians investigators: report of the ad hoc committee of the AAMC. Clin Res 1980; 28:85-93

15. Kelley WN: Personnel needs for clinical research: role of the clinical investigator. Clin Res 1985; 33:100-104

16. Raphael B, Dunne M, Byrne G: A research seminar programme for doctoral candidates in psychiatry. Aust N Z J Psychiatry 1990; 24:207-213

17. Sadeghi-Nejad A, Marquardt MM: Academic physicians: today's dinosaurs? Am J Med 1991; 90:371-373

18. National Research Council/Committee on a Study of National Needs for Biomedical and Behavioral Research Personnel: 1979 Report. Washington, DC, National Academy of Sciences, 1979

19. Stein M: Psychiatrist's role in psychiatry research. Arch Gen Psychiatry 1970; 22:481-489

20. Burke Jr JD, Pincus HA, Pardes HP: The clinician-researcher in psychiatry. Am J Psychiatry 1986; 143:968-975

21. Haviland MG, Pincus HA, Dial TH: Career, research involvement, and research fellowship plans of potential psychiatrists. Arch Gen Psychiatry 1987; 44:493-496

22. Garfinkel PE, Goldbloom DS, Kaplan AS, Kennedy SH: The clinician-investigator in psychiatry: 1-values and problems. Can J Psychiatry 1989; 34:361-363

23. Reich J, Black DW, Jarjoua D: Architecture of research psychiatry, 1953 to 1983. Arch Gen Psychiatry 1987; 44:311-313

24. Pincus HA: Research and clinical training in psychiatry: inputs and outputs. Psychiatr $Q$ 1991; 62:121-133 
25. Janowsky DS, Glick ID, Lash L, et al: Psychobiology and psychopharmacology: issues in clinical research training. J Clin Psychopharmacol 1986; 6:1-7

26. Davis WK, Kelley WN: Factors influencing decisions to enter careers in clinical investigation. J Med Educ 1982; 57:275-281

27. Brancati FL, Mead LA, Levine DM, Martin D, Margolis S, Klag MJ: Early predictors of career achievement in academic medicine. JAMA 1992; 267:1372-1376

28. Pardes H: Neuroscience and psychiatry: marriage or coexistence. Am J Psychiatry 1986; 143:1205-1212

29. Detre T: The future of psychiatry. Am J Psychiatry 1987; 144:621-625

30. Pasnau RO: The remedicalization of psychiatry. Hosp Community Psychiatry 1987; 38:145-151

31. Culliton BJ: NIH starts review of training programs. Science 1984; 223:149-150

32. Resier MF: Are psychiatric educators "losing their mind"? Am J Psychiatry 1988; 145:148153

33. Kirby RL: Medical education as preparation for research. Can Med Assoc J 1986; 134:988-989

34. Movsesian MA: Effect on physician-scientists of the low funding rate of NIH grant applications. N Engl J Med 1990; 322:1602-1604

35. Beaty HN, Babbott D, Higgins EJ, et al: Research activities in academic departments of medicine. Ann Intern Med 1986; 104:90-97

36. Greco RS, Donets AP, Mackenzie JW, et al: Career development of residents in university and independent training programs: the influence of special training fellowships, types of practice, specialization, and research. Surgery 1986; 100:312-319

37. Evered DC, Anderson J, Griggs P: The correlates of research success. Br Med J 1987; 295:241-246

38. Eaton DG, Thong YH: The Bachelor of Medical Science research degree as a start for clinician-scientists. Med Educ 1985; 19:445-451

39. Bradford WD, Pizzo S, Christakos AC: Careers and professional activities of graduates of medical scientist training program.J Med Educ 1986; 61:915-918

40. Angell M: Publish or perish: a proposal. Ann Intern Med 1986; 104:261-262

41. Freedman DX: Of chairs and stools: or, what's academic about academic medicine? Perspect Biol Med 1991; 35:87-96

42. Jones J, Dougherty J, Cannon L, et al: Teaching research in the emergency medicine curriculum. Ann Emergency Med 1987; 16:347-353 